\title{
Considerações sobre os Diferentes Graus de Prazer que Oferecem o Aspecto da Natureza e o Estudo de suas Leis*
}

\author{
AleXANDER VON HumboldT
}

(...)

Se consideramos o estudo dos fenômenos físicos não em suas relações com as necessidades materiais da vida, mas em sua influência geral sobre os progressos intelectuais da humanidade, o mais elevado e importante resultado desta investigação é o conhecimento da conexão existente entre as forças da Natureza e o sentimento íntimo de sua mútua dependência. A intuição dessas relações é o que amplia nossas perspectivas e enobrece nossos prazeres. Este alargamento de horizontes é resultado da observação, da meditação e do espírito do tempo em que se concentram todas as direções do pensamento. A história revela a quem sabe penetrar através das camadas dos séculos precedentes até as raízes profundas de nossos conhecimentos como, desde há milhares de anos, o gênero humano trabalhou para conhecer, nas mutações incessantemente renovadas, a invariabilidade das leis naturais e para conquistar progressivamente uma grande parte do mundo físico pela força da inteligência. Interrogar os anais da história é seguir essa trilha misteriosa, sobre a qual a imagem do Cosmos revelada primitivamente ao sentido interior como um vago pressentimento da harmonia e da ordem do Universo, se oferece hoje como fruto de longas e sérias observações.

\footnotetext{
*FONTE: HUMBOLDT, Alexander Von (1845-1862): Cosmos. Ensaio de uma descrição física do mundo. 5 vol. Traduzido de MENDOZA, Josefina G. et alii (orgs). El Pensamiento Geográfico. Madrid, Alianza, 1982, pp. 159-162, por Sérgio Nunes Pereira.
} 
A essas duas épocas na consideração do mundo exterior, ao primeiro lampejo da reflexão e no período de civilização avançada, correspondem dois gêneros de prazeres. O primeiro, próprio da simplicidade primitiva das épocas antigas, nasce da percepção da ordem expressa pela sucessão regular dos corpos celestes e o desenvolvimento progressivo da organização; o outro, resulta do conhecimento exato dos fenômenos. Desde o momento em que o homem, ao interrogar a Natureza, não se limita à observação, mas articula fenômenos sob determinadas condições, desde que recolhe e registra os fatos para estender a investigação para além da curta duração de sua existência, a Filosofia da Natureza se despoja das formas vagas que a caracterizava desde sua origem; adota um caráter mais sério, confronta o valor das observações, já não adivinha, combina e raciocina. As afirmações dogmáticas dos séculos anteriores se conservam somente nas crenças do povo e das classes que, por sua falta de ilustração, a ele se assemelham, e se perpetuam sobretudo em algumas doutrinas que se revestem de uma aparência mística para ocultar sua debilidade. As linguagens carregadas de expressões figuradas conservam os traços dessas primeiras intuições. Um reduzido número de símbolos, produto de uma feliz inspiração em tempos primitivos, é capaz de ir tomando pouco a pouco formas vagas e, se melhor interpretados, incorporarar-se inclusive na linguagem científica.

A Natureza, considerada por meio da razão, quer dizer, submetida em seu conjunto à ação do pensamento, é a unidade na diversidade dos fenômenos, a harmonia entre as coisas criadas que diferem por sua forma, por sua constituição e pelas forças que as animam; é o Todo animado por um sopro de vida. A realização mais importante de um estudo racional da Natureza é apreender a unidade e a harmonia existentes nesta imensa acumulação de coisas e forças; assumir com o mesmo interesse tanto os resultados das descobertas dos séculos passados como o que se deve às investigações dos tempos atuais e analisar as características dos fenômenos sem sucumbir sob sua massa. Penetrando nos mistérios da Natureza, descobrindo seus segredos e dominando pela ação do pensamento os materiais recolhidos mediante a observação, é como o homem pode mostrar-se mais digno de seu alto destino.

Se refletimos acerca dos diferentes graus de prazer que suscita a contemplação da Natureza, descobrimos que, em primeiro lugar, deve colocar-se um tipo de impressão inteiramente independente do conhecimento profundo dos fenômenos físicos e independente também do caráter individual da paisagem e da fisionomia da região que nos rodeia. Em qualquer lugar de planura monótona, sem mais limites que o horizonte, onde a vegetação homogênea de arbustos ou gramíneas cobre o solo, em qualquer lugar onde as ondas do mar banham a costa e marcam sua passagem com estrias verdes de algas, o sentimento da Natureza, grande e livre, embarga nossa alma e nos revela, como por uma misteriosa inspiração, que as forças do Universo estão submetidas a leis. O simples contato do homem com a Natureza, esta influência dos grandes espaços, ou do "ar livre", como dizem outras línguas com maior beleza, exercem uma ação de sossego, aplacam a dor e acalmam as paixões, ao mesmo tempo que a alma se sente intimamente agitada. Esta 
benéfica influência o homem a recebe em todas as partes, qualquer que seja a zona que habite e qualquer que seja o grau de cultura intelectual que tenha alcançado. $O$ tanto de arrebatador e de solene que há nas impressões que assinalamos se deve ao pressentimento da ordem e às leis, que surge espontaneamente do simples contato com a Natureza, assim como do contraste que oferecem os estreitos limites de nosso ser com a percepção do infinito que se revela onde quer que seja, na abóbada estrelada do céu, na planície que se estende mais além de nossa vista, no brumoso horizonte do oceano.

Outro tipo de prazer é o produzido pela configuração concreta da paisagem, pela forma da superfície do globo em uma região determinada. As impressões deste gênero são mais vivas, melhor definidas, mais de acordo com certos estados de ânimo. Algumas vezes é a imensidão das massas, a luta dos elementos isolados ou a desolação das estepes, como no norte da Ásia, o que excita nossa emoção; outras, sob o domínio de sentimentos mais suaves, a suscita o aspecto dos campos cobertos por abundantes colheitas, a casa na margem de uma torrente ou a fecundidade acrescentada ao solo vencido pelo arado.

\section{(..)}

A tentativa de decompor em seus diversos elementos a magia do mundo físico está cheia de riscos, porque o caráter fundamental de uma paisagem e de qualquer cenário importante da Natureza deriva da simultaneidade de idéias e de sentimentos que suscita no observador. O poder da Natureza se manifesta, por assim dizer, na conexão de impressões, na unidade de emoções e sentimentos que se produzem, de certo modo, de uma só vez. Se queremos detectar suas origens parciais, é preciso recuar por meio da análise à individualidade das formas e à diversidade das forças...

\section{(...)}

Não se trata neste ensaio da Física do Mundo de reduzir o conjunto dos fenômenos sensíveis a um pequeno número de princípios abstratos, sem outra base que não a razão pura. A Física do Mundo que tento expor não pretende elevar-se às perigosas abstrações de uma ciência puramente racional da Natureza; é uma Geografia Física unida à descrição dos espaços celestes e dos corpos que se encontram nesses espaços. Alheio às preocupações da Filosofia puramente especulativa, meu ensaio sobre o Cosmos é uma consideração do Universo fundada em um empirismo racional, quer dizer, sobre um conjunto de fatos registrados pela ciência e submetido à ação de um entendimento que compara e combina. Só dentro desses limites a obra que empreendi se entronca com o tipo de trabalho a que consagrei minha longa trajetória científica. Não me aventuro a entrar em um campo onde não saberia mover-me com desembaraço ainda que talvez outros possam tentá-lo com êxito. A unidade que trato de detectar no desenvolvimento dos grandes fenômenos do Universo é a que oferecem as concepções históricas. Tudo que se relacione com individualidades acidentais, com o componente variável da realidade, tanto se trate 
da forma dos seres como da agrupação dos corpos, ou da luta dos homens com os elementos e dos povos com os povos, não pode ser deduzido só com idéias, ou seja, racionalmente construído.

Creio que a descrição do Universo e a história das sociedades se encontram no mesmo grau de empirismo, mas, submetendo os fenômenos físicos e os acontecimentos ao trabalho da inteligência e remontando a suas causas por meio da razão, se confirma cada vez mais a antiga crença de que as forças inerentes à matéria e as que regem o mundo moral exercem sua ação sob o império de uma necessidade primordial e segundo movimentos que se repetem de forma periódica ou em intervalos irregulares. Esta necessidade das coisas, este encadeamento oculto mas permanente, esta renovação periódica no desenvolvimento progressivo das formas, dos fenômenos e dos acontecimentos, constituem a Natureza, que obedece a um impulso primário determinado. A Física, como seu próprio nome indica, se limita a explicar os fenômenos do mundo material por meio das propriedades da matéria. $\mathrm{O}$ objeto mais elevado das ciências experimentais é, portanto, chegar ao conhecimento das leis e generalizá-las progressivamente. Tudo que esteja mais além não é do domínio da Física do Mundo e pertence a um gênero de especulações mais elevadas. Emmanuel Kant, um dos raros filósofos que até agora não foram acusados de heresia, assinalou os limites das explicações físicas com uma extraordinária sagacidade em seu célebre "Ensaio sobre a teoria e a construção dos Céus", publicado em Koenisberg em 1755.

(...)

\section{HUMBOLDT - Dados Biobibliográficos}

1769: Nascimento.

c.1780-1790: Pertencendo a uma família aristocrática prussiana, recebe uma educação esmerada através de preceptores particulares.

1790-1792: Estudos na Academia de Minas de Freiberg.

1790-1798: Primeiros trabalhos científicos, geralmente sobre questões específicas do domínio das ciências naturais. Exemplos: "Observação mineralógica de alguns basaltos do Reno" (1790) e artigos nos Annalles de Chimie - Paris (1797-98).

1799-1804: Viagem pelas Américas.

1805-1826: Período em que Humboldt escreve a maior parte de seus trabalhos derivados diretamente das viagens, publicando em média três estudos por ano. Os mais importantes compõem os volumes de "Quadros da Natureza" (1808) e "Viagem às Regiões Equinociais do Novo Continente", concluída apenas em 1834. Nesta obra gigantesca, dedicada quase inteiramente ao estudo de aspectos físicos, figuram também os ensaios políticos sobre o Reino de Nova Espanha (1811) e sobre a Ilha de Cuba (1826).

1827-1828: Ciclo de 61 conferências na Universidade de Berlim. 
1828: Viagem pela Ásia Central, da qual resultam "Fragmentos de Geologia e de Climatologia Asiática" (1831) e "Ásia Central. Pesquisa sobre as Cadeias de Montanha e Climatologia Comparada" (1843).

1845-1858: Período de publicação dos quatro primeiros volumes do "Cosmos". 1859: Morte.

1862: Publicação póstuma do vol. V do "Cosmos". 